\title{
Clinicopathologic characteristics and prognosis of Borrmann type IV gastric cancer: a meta-analysis
}

Yifan Luo ${ }^{\dagger}$, Peng Gao ${ }^{\dagger}$, Yongxi Song, Jingxu Sun, Xuanzhang Huang, Junhua Zhao, Bin Ma, Yuan Li and Zhenning Wang ${ }^{*}$

\begin{abstract}
Background: The clinicopathologic features and surgical treatment strategy of Borrmann type IV (B-4) gastric cancer remains controversial. This meta-analysis was conducted to evaluate the clinicopathologic features of patients with B-4 gastric cancer and to assess whether or not non-curative resection improved prognosis.

Methods: PubMed and Embase were searched for relevant articles. Statistical analysis was performed using RevMan (version 5.2). The odds ratio (OR), risk ratio (RR), hazard ratio (HR) with $95 \%$ confidence interval (CI), and weighted average of median survival times were calculated as effect values.

Results: Fifteen studies were included. Compared with Borrmann type "others" (B-O), B-4 had a higher incidence of poorly differentiated carcinoma $(\mathrm{OR}=4.92 ; 95 \% \mathrm{Cl}=3.10-7.83 ; P<0.01)$, lymph node metastases $(\mathrm{OR}=2.13 ; 95 \%$ $\mathrm{Cl}=1.88-2.41 ; P<0.01)$, peritoneal metastases $(\mathrm{OR}=3.91 ; 95 \% \mathrm{Cl}=3.37-4.54 ; P<0.01)$, serosal invasion $(\mathrm{OR}=3.66$; $95 \% \mathrm{Cl}=2.91-4.60 ; P<0.01)$, and lymphatic invasion $(\mathrm{OR}=1.39 ; 95 \% \mathrm{Cl}=1.02-1.91 ; P=0.04)$. B-4 patients with non-curative resection were associated with a worse survival rate $(\mathrm{HR}=2.83 ; 95 \% \mathrm{Cl}=2.35-3.40 ; P<0.01)$ than patients with curative resection; however, B-4 patients with non-curative resection had a better survival rate (1-year: $\mathrm{RR}=0.70,95 \% \mathrm{Cl}=0.63-0.77 ; P<0.01 ; 2$-year: $\mathrm{RR}=0.90,95 \% \mathrm{Cl}=0.85-0.94 ; P<0.01)$ than patients with non-resection.

Conclusions: Our meta-analysis indicated that B-4 patients were associated with poor tumor differentiation, lymph node metastases, peritoneal metastases, serosal invasion, lymphatic invasion, and prognosis. Curative resection may increase the survival rate for B-4 patients. If it is not possible to perform a curative resection, a non-curative resection may improve the prognosis.
\end{abstract}

Keywords: Gastric cancer, Borrmann type IV, Clinicopathologic characteristic, Prognosis, Meta-analysis

\section{Background}

Gastric cancer is a common malignant disease and remains the third most frequent cause of cancer deaths worldwide [1,2]. The classification of advanced gastric cancer according to Borrmann's criteria is presently accepted by many surgeons, endoscopists, and radiologists worldwide. According to this classification, Borrmann type IV (B-4) gastric cancer is defined as a lesion which

\footnotetext{
* Correspondence: josieon826@sina.cn

${ }^{\dagger}$ Equal contributors

Department of Surgical Oncology and General Surgery, First Hospital of China Medical University, Shenyang City, Liaoning Province, People's Republic of China
}

diffusely infiltrates to the gastric wall without ulceration or distinct elevation [3]. The incidence of B-4 gastric cancer is approximately $10-20 \%$ of all gastric cancer [4]. Several studies have analyzed the clinicopathologic features of patients with B-4 gastric cancer, but controversy still remains with respect to the incidence of hepatic metastases and vascular invasion [5-8]. In addition, B-4 gastric cancer usually has a poor prognosis; the 5year survival rate after gastrectomy has been reported to be approximately $30 \%[8,9]$. Surgical resection is the most suitable treatment for gastric cancer [10], but the surgical treatment strategy for B-4 patients is controversial [11-14]. Some investigations have reported that 
non-curative resection may improve the prognosis of patients with B-4 gastric cancer [13]. At the same time, it was reported by another group that there was no statistical difference between the prognosis of patients with non-curative resection and those with non-resection [14]. Some researchers even believe that B-4 gastric carcinoma is not surgically curable based on the poor outcomes after surgery $[11,12]$. The purposes of our metaanalysis were to compare the clinicopathologic characteristics (e.g., gender ratio, pathologic type, tumor metastases, and invasion) between B-4 gastric cancer and Borrmann type "others" (B-O) and to evaluate the effectiveness of surgical treatment for patients with B-4 gastric cancer.

\section{Methods}

\section{Search strategy}

Two investigators (Yifan Luo and Peng Gao) performed independent searches of the electronic databases (PubMed and Embase) from inception to January 2015. The search strategy included the keywords "Borrmann" and "gastric cancer" and the strategy was changed according to different requirements for each database. Both published and unpublished articles were included, and no language restriction was applied. The reference lists of all selected studies were further searched to identify other additional pertinent articles.

\section{Inclusion and exclusion criteria}

All observational and experimental studies that evaluated survival of patients with B-4 gastric cancer treated by non-curative resection were considered, and the studies that compared the clinicopathologic characteristics of B-4 and B-O gastric carcinomas were included in the present study. Articles without full text and data needed that could not be acquired from the authors were excluded. In addition, letters to the editor without useful data, case reports, and editorials were excluded. If the same authors reported multiple investigations conducted during the same period, we only utilized the most complete reports in the present study.

\section{Data extraction}

Two independent researchers extracted data from each study using a predefined table. The following information was extracted from the included study: author, publication time, country, sample size, clinicopathologic characteristics, and major end point. The pathologic type was separated into well (tubular and papillary adenocarcinomas)- and poorly differentiated (poorly differentiated adenocarcinoma, mucinous carcinoma, and signet-ring cell carcinoma) types. If the article did not provide the hazard ratio (HR) for overall survival, we used Engauge Digitizer 4.1 software to distinguish the Kaplan-Meier curves and extract the HRs of overall survival.

\section{Quality assessment for included studies}

The quality of each included study was independently evaluated using the Newcastle-Ottawa Scale [15] by two investigators, with scores $\geq 5$ indicating high quality.

\section{Statistical analysis}

Statistical analysis was performed with RevMan (version 5.2; Cochrane Collaboration). The odds ratio (OR) and risk ratio (RR) with $95 \%$ confidence interval (CI) were used for the analysis of dichotomous data, and the weighted average of the median survival times were used for continuous data. The HR and $95 \% \mathrm{CI}$ for the overall survival were calculated with the method reported by Tierney et al. [16]. We assessed the heterogeneity between studies using the chi-square test, which indicates the presence of significant heterogeneity at a $P$ value $<0.05$. At the same time, $I^{2}$ was used to assess heterogeneity. An $I^{2}>50 \%$ was considered to be statistically significant. For outcomes in which significant heterogeneity was observed, a random effects model was used; otherwise, a fixed effects meta-analysis was conducted. The assessment of publication bias was evaluated using the funnel plot.

\section{Results}

The included literature and methodologic quality

A flow diagram of the selection process is shown in Fig. 1. The initial search identified 1906 studies for the meta-analysis; 1879 studies were excluded after a review of the titles and abstracts. After full text assessment of the 27 eligible studies, 15 were included in this metaanalysis according to our inclusion and exclusion criteria. All included studies were retrospective. The main characteristics of each included study are listed in Table 1 . The quality of the included studies was assessed according to the Newcastle-Ottawa Scale; most of the included studies were high quality based on the scores $(>5)$.

\section{Clinicopathologic characteristics and prognosis}

We demonstrated that patients with B-4 carcinoma had significantly worse survival rates than patients with other types of carcinomas $(\mathrm{HR}=2.64 ; 95 \% \mathrm{CI}=$ 2.38-2.93; $P<0.01$; Fig. 2a). Ten studies provided data regarding the gender ratio. The female-to-male ratio in the B-4 group was significantly higher than that in the B-O group (0.82 [940/1140] vs. 0.44 [3904/8804]; pooled $\quad \mathrm{OR}=1.87 ; \quad 95 \% \quad \mathrm{CI}=1.70-2.06 ; \quad P<0.01$; Fig. 2b). In the pathologic type subset, seven studies involving 12,836 patients were divided into two principal subgroups (well- and poorly differentiated). In 


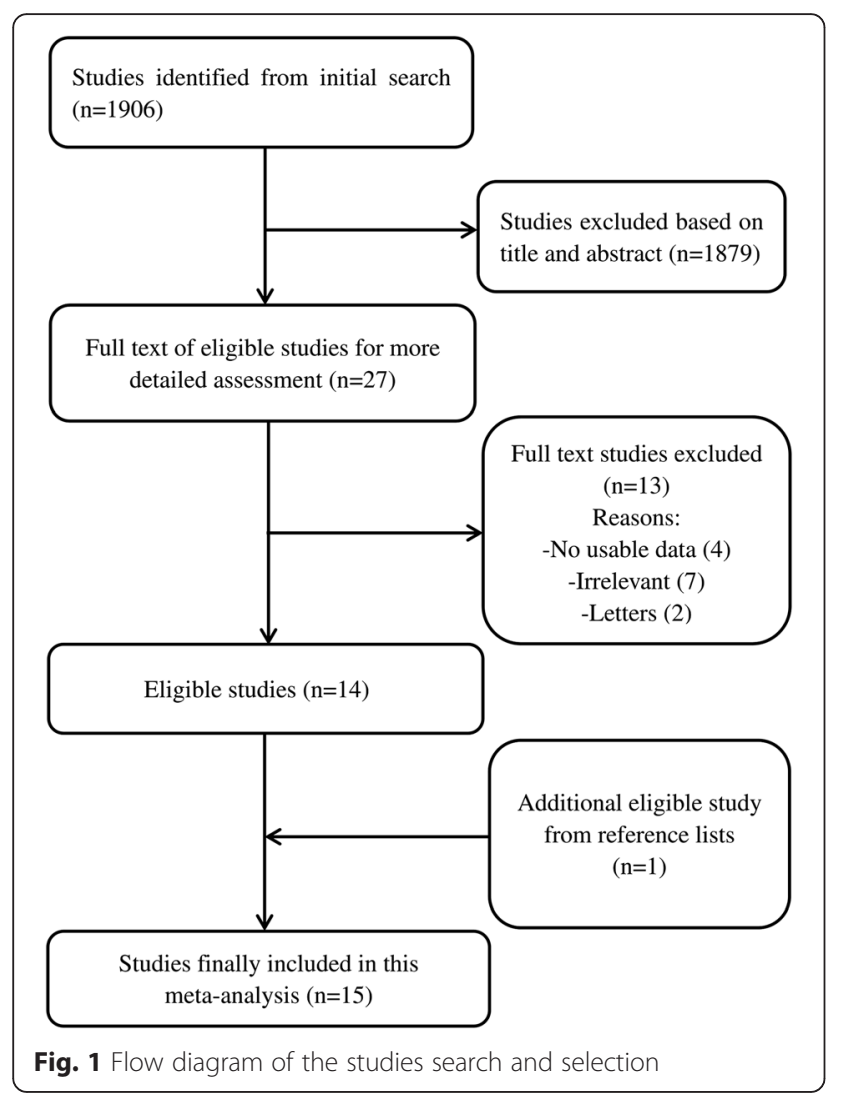

the poorly differentiated group, the proportion of B-4 patients was significantly higher than the B-O patients (87.98 \% [1530/1739] vs. $60.39 \%$ [6701/11,097]; pooled $\mathrm{OR}=4.92 ; \quad 95 \% \quad \mathrm{CI}=3.10-7.83 ; \quad P<0.01$; Fig. 2c).

In addition, ten trials $[5-9,12,14,17-19]$ showed data on tumor metastases and invasion, which we distributed into six subsets (lymph node metastases, hepatic metastases, peritoneal metastases, lymphatic invasion, serosal invasion, and vascular invasion). The different types of metastases and invasion patterns resulted in different outcomes. A higher ratio of B-4 patients with lymph node metastases (84.38 \% [1755/2080] vs. $71.29 \%$ [9059/ $12,708]$; pooled $\mathrm{OR}=2.13 ; 95 \% \mathrm{CI}=1.88-2.41 ; P<0.01$; Fig. 3a), peritoneal metastases (27.82\% [358/1287] vs. $9.36 \%$ [755/8065]; pooled $\mathrm{OR}=3.91 ; 95 \% \mathrm{CI}=3.37-$ 4.54; $P<0.01$; Fig. $3 \mathrm{~b})$, serosal invasion $(82.31 \%[1712 /$ $2080]$ vs. $60.84 \%$ [7731/12,708]; pooled $\mathrm{OR}=3.66 ; 95 \%$ $\mathrm{CI}=2.91-4.60 ; P<0.01 ;$ Fig. $3 \mathrm{c})$, and lymphatic invasion (62.13\% [584/940] vs. $54.55 \%$ [2983/5468]; pooled OR $=1.39 ; 95 \% \mathrm{CI}=1.02-1.91 ; P=0.04$; Fig. $3 \mathrm{~d}$ ) was shown compared with $\mathrm{B}-\mathrm{O}$ patients; however, there were no statistically significant differences in vascular invasion (pooled OR $=1.05 ; 95 \% \mathrm{CI}=0.85-1.30 ; P=0.62$; Fig. 4a) and hepatic metastases (3.81\% [49/1287] vs. $4.98 \%$ [402/8065]; pooled $\mathrm{OR}=0.68 ; 95 \% \mathrm{CI}: 0.39-1.20 ; P=$ 0.19; Fig. 4b). Sensitivity analysis was performed by omitting each individual study. When we eliminated the Ma study [7], B-4 patients had a lower incidence of hepatic metastases (3.05\% [35/1148] vs. $4.98 \%$ [364/7311]; pooled $\mathrm{OR}=0.55 ; 95 \% \mathrm{CI}=0.39-0.79 ; P<0.01$; Fig. 4c), and statistically significant heterogeneity between the remaining studies was not detected $\left(P=0.31, I^{2}=16 \%\right)$.

\section{Efficiency of surgical treatment}

A quantitative meta-analysis using the data from four studies revealed that non-curative resection compared with curative resection in B-4 patients was associated with a worse survival rate $(\mathrm{HR}=2.83 ; 95 \% \mathrm{CI}=2.35$ 3.40; $P<0.01$; Fig. 5a). Six studies reported median survival times for B- 4 patients after non-curative resection or non-resection [13, 14, 20-23]. In these studies, 434 patients underwent non-curative resection and 304 patients underwent non-resections, such as an exploratory laparotomy. In the non-curative resection group, the weighted average of the median survival time was 9.8 months, whereas the weighted average of the median survival time was 5.2 months in the other group. Five studies provided data regarding the 1- and 2-year survival rates for $\mathrm{B}-4$ patients. The $1(\mathrm{RR}=0.70,95 \% \mathrm{CI}=$ $0.63-0.77 ; P<0.01$; Fig. $5 \mathrm{~b}$ )- and 2-year survival rates $(\mathrm{RR}=0.90,95 \% \mathrm{CI}=0.85-0.94 ; P<0.01$; Fig. $5 \mathrm{c})$ in the non-curative resection group had a better prognosis than in the non-resection group. Publication bias was examined by the funnel plot. There was no evidence of publication bias among these comparisons.

\section{Discussion}

Although advances in diagnostic techniques and treatment methods have improved overall treatment outcomes for gastric cancer patients, the prognosis of B-4 gastric cancer remains poor. Patients with B-4 gastric cancer are always in an advanced stage when diagnosed, and some authorities attribute this finding to the special clinicopathologic characteristics of the tumor [13]; however, the clinicopathologic characteristics and surgical treatment strategy of B-4 patients is always in dispute. Based on our present meta-analysis, patients with B-4 gastric cancer had a higher female-to-male ratio, more poorly differentiated carcinomas, more lymph node metastases, more peritoneal metastases, more serosal invasion, more lymphatic invasion, and a poorer prognosis. It has been reported that patients with a poorly differentiated pathologic type of gastric cancer are characterized by lymph node metastases, serosal invasion, peritoneal dissemination, and advanced stage [24]. Some investigators have reported that B-4 gastric cancer predominates in females and in undifferentiated histology, invades the serosal surface, involves lymph nodes more frequently, and has a high incidence of peritoneal 
Table 1 Characteristics of included studies

\begin{tabular}{|c|c|c|c|c|c|c|c|c|c|c|c|c|c|}
\hline \multirow[t]{2}{*}{ Author } & \multirow[t]{2}{*}{ Year } & \multirow[t]{2}{*}{ Country } & \multirow{2}{*}{$\begin{array}{l}\text { B-4/B-O } \\
\text { (patient } \\
\text { number) }\end{array}$} & \multirow{2}{*}{$\begin{array}{l}\text { B-4 } \\
\text { incidence } \\
(\%)\end{array}$} & \multicolumn{4}{|c|}{ B-4 with non-curative resection } & \multicolumn{4}{|c|}{ B-4 with non-resection } & \multirow[t]{2}{*}{$\mathrm{NO}$} \\
\hline & & & & & $\begin{array}{l}\text { Patient } \\
\text { number }\end{array}$ & $\begin{array}{l}\text { Median } \\
\text { survival } \\
\text { time } \\
\text { (month) }\end{array}$ & $\begin{array}{l}\text { 1-year } \\
\text { survival }\end{array}$ & $\begin{array}{l}\text { 2-year } \\
\text { survival }\end{array}$ & $\begin{array}{l}\text { Patient } \\
\text { number }\end{array}$ & $\begin{array}{l}\text { Median } \\
\text { survival time (month) }\end{array}$ & $\begin{array}{l}\text { 1-year } \\
\text { survival }\end{array}$ & $\begin{array}{l}\text { 2-year } \\
\text { survival }\end{array}$ & \\
\hline $\begin{array}{l}\text { Maehara } \\
\text { [6] }\end{array}$ & 1992 & Japan & $194 / 919$ & 17.4 & NA & NA & NA & NA & NA & NA & NA & NA & 6 \\
\hline $\begin{array}{l}\text { Kitamura } \\
{[14]}\end{array}$ & 1995 & Japan & $102 / 563$ & 15.3 & 50 & 11.1 & NA & NA & 13 & 6.2 & NA & NA & 5 \\
\hline $\begin{array}{l}\text { Tanigawa } \\
{[17]}\end{array}$ & 1998 & Japan & $33 / 169$ & 16.3 & NA & NA & NA & NA & NA & NA & NA & NA & 6 \\
\hline Otsuji [12] & 1999 & Japan & $150 / 698$ & 17.7 & NA & NA & NA & NA & NA & NA & NA & NA & 5 \\
\hline Yokota [19] & 1999 & Japan & $88 / 309$ & 22.2 & NA & NA & NA & NA & NA & NA & NA & NA & 6 \\
\hline Kodera [22] & 2001 & Japan & $70 / 0$ & NA & 31 & 9.7 & $35.48 \%$ & $12.90 \%$ & 11 & 8 & $27.27 \%$ & $9.09 \%$ & 6 \\
\hline Chen [5] & 2002 & China & $103 / 604$ & 14.6 & NA & NA & NA & NA & NA & NA & NA & NA & 5 \\
\hline Kim [18] & 2002 & Korea & $\begin{array}{l}199 / \\
1607\end{array}$ & 11 & NA & NA & NA & NA & NA & NA & NA & NA & 5 \\
\hline Yook [13] & 2005 & Korea & $\begin{array}{l}370 / \\
3693\end{array}$ & 9.1 & 51 & 11 & $47.06 \%$ & $13.73 \%$ & 90 & 7 & $26.67 \%$ & $11.10 \%$ & 6 \\
\hline $\begin{array}{l}\text { Nashimoto } \\
{[23]}\end{array}$ & 2007 & Japan & $\begin{array}{l}770 / \\
8474\end{array}$ & 8.3 & 254 & 9 & $37.80 \%$ & $14.57 \%$ & 116 & 4.33 & $7.76 \%$ & $0.86 \%$ & 5 \\
\hline An [8] & 2008 & Korea & $\begin{array}{l}555 / \\
3636\end{array}$ & 13.2 & NA & NA & NA & NA & NA & NA & NA & NA & 4 \\
\hline Li [9] & 2009 & China & $\begin{array}{l}517 / \\
3449\end{array}$ & 13 & NA & NA & NA & NA & NA & NA & NA & NA & 5 \\
\hline $\begin{array}{l}\text { Accetta } \\
{[20]}\end{array}$ & 2011 & Brazil & $123 / 836$ & 12.8 & 16 & 10 & NA & $13.00 \%$ & 55 & 3 & NA & 0 & 5 \\
\hline Gao [21] & 2011 & China & $118 / 0$ & NA & 32 & 11.6 & $40.60 \%$ & $6.20 \%$ & 19 & 6.1 & $15.80 \%$ & 0 & 5 \\
\hline Ma [7] & 2012 & China & $139 / 754$ & 15.6 & NA & NA & NA & NA & NA & NA & NA & NA & 7 \\
\hline
\end{tabular}

NOS Newcastle-Ottawa Scale, B-4 Borrmann type IV, B-O Borrmann type "others", NA not applicable

dissemination $[6,9,13,14]$. Indeed, our results are consistent with these studies.

According to our findings, patients with B-4 gastric cancer had a lower incidence of hepatic metastases, but the difference was not statistically significant. Further sensitivity analysis revealed that the Ma study [7] was the primary cause of the heterogeneity. After eliminating the Ma study [7], the incidence of hepatic metastases was significantly lower in patients with B4 gastric cancer than patients with $\mathrm{B}-\mathrm{O}$, and there was no statistically significant heterogeneity between the remaining studies. In the hepatic metastases comparison, we found that patients in the Ma study [7] had a higher serosal invasion incidence than other studies. The high proportion of patients with an advanced stage might be the source of the heterogeneity. Maehara [25] suggested that hepatic metastases were more frequent in patients with Borrmann type 2 and 3 gastric cancer. Adacki [26] reported that most poorly differentiated carcinomas are hypovascular and vascular irregularity often exists. We reasoned that B4 gastric cancer rarely develops blood-borne metastases to the liver might due to the large proportion of poorly differentiated carcinomas.

The optimal treatment of patients with B-4 gastric cancer remains a matter of debate. In 1989, Aranha [11] concluded that B-4 gastric carcinoma is not a surgically curable disease because of the poor post-operative survival; however, most investigators believe that the prognosis is significantly worse in B-4 patients who undergo a non-curative resection than a curative resection $[6,7$, $9,14,18]$; our results are consistent with their conclusion $(\mathrm{HR}=2.83 ; 95 \% \mathrm{CI}=2.35-3.40 ; P<0.01)$. This difference may be attributed to the advances in various diagnostic and treatment modalities in recent decades. In Japan, some researchers suggested that aggressive extended surgery, such as a left upper abdominal exenteration plus Appleby's method (LUAE + Apl), could improve the survival of patients with B-4 stage III gastric cancer $[27,28]$. At present, most physicians do not recommend LUAE + Apl because it is not effective for patients with stage IV gastric cancer and may cause severe post-operative complications. Besides, some researchers believe that extended lymphadenectomy should be 


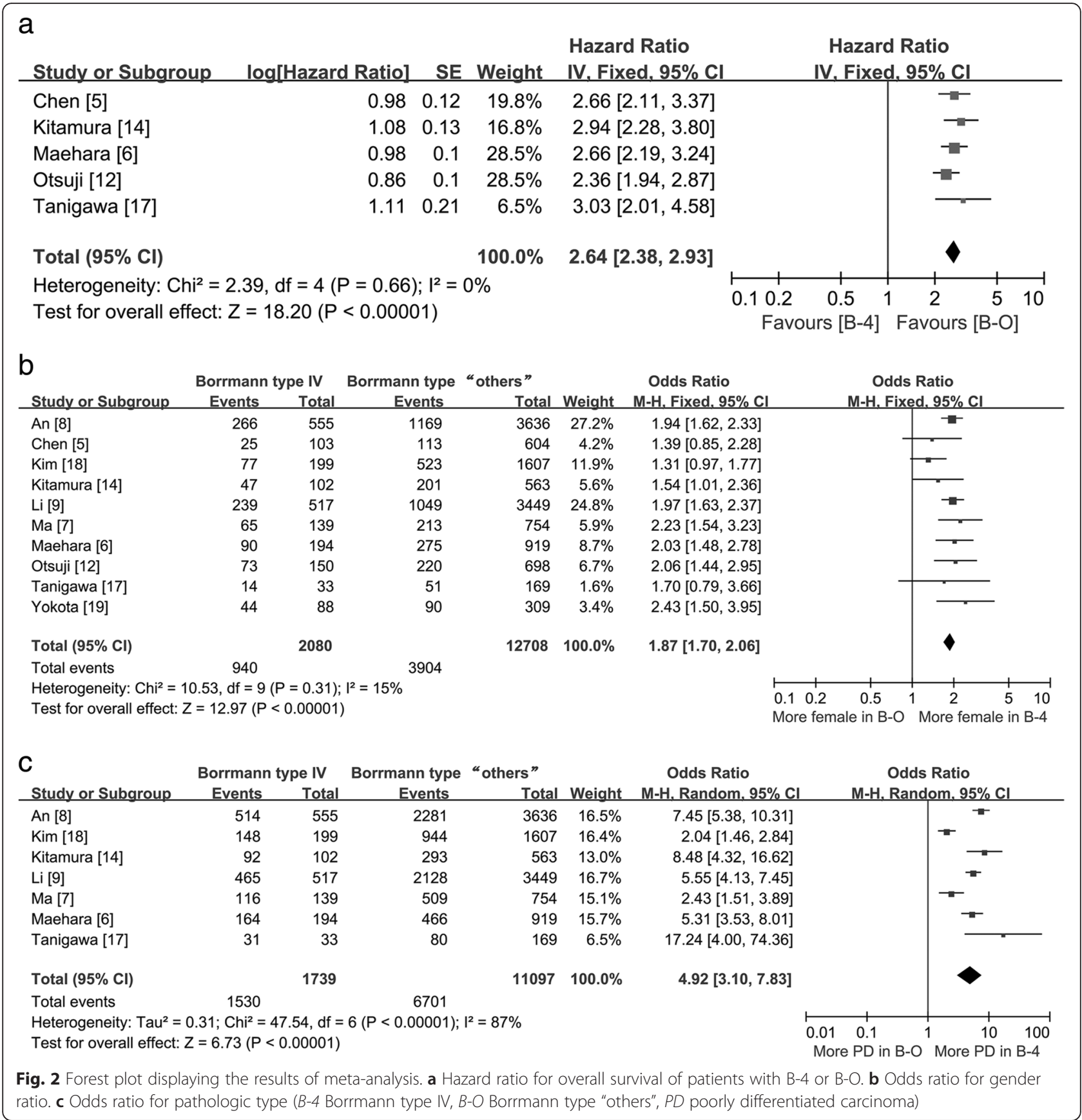

performed if patient's clinical condition allowed, because it may allow a better assessment of nodal stations and decrease the chance of stage worsening [20].

Moreover, there is some controversy regarding the role of non-curative resection for survival. Kodera [22] reported that such an aggressive surgical attitude is likely to prove futile for B-4 gastric cancer patients. Yook [13] demonstrated that non-curative resection may lengthen the survival time in B-4 patients with peritoneal dissemination. We found that the 1-year survival rate in the non-curative resection group had a significantly better prognosis than in the non-resection group $(R R=0.70$, $95 \% \mathrm{CI}=0.63-0.77 ; P<0.01)$. Although the difference in the 2-year survival rate between the two groups was smaller $(\mathrm{RR}=0.90,95 \% \mathrm{CI}=0.85-0.94 ; P<0.01)$, statistical differences still existed. Because the patients without curative resection do not usually survive 2 years, we could not compare the 3- or 5-year survival between the non-resection and non-curative resection groups. Based on our research, the weighted average of the median survival time in the non-curative resection group (9.8 months) was longer than in the non-resection group 


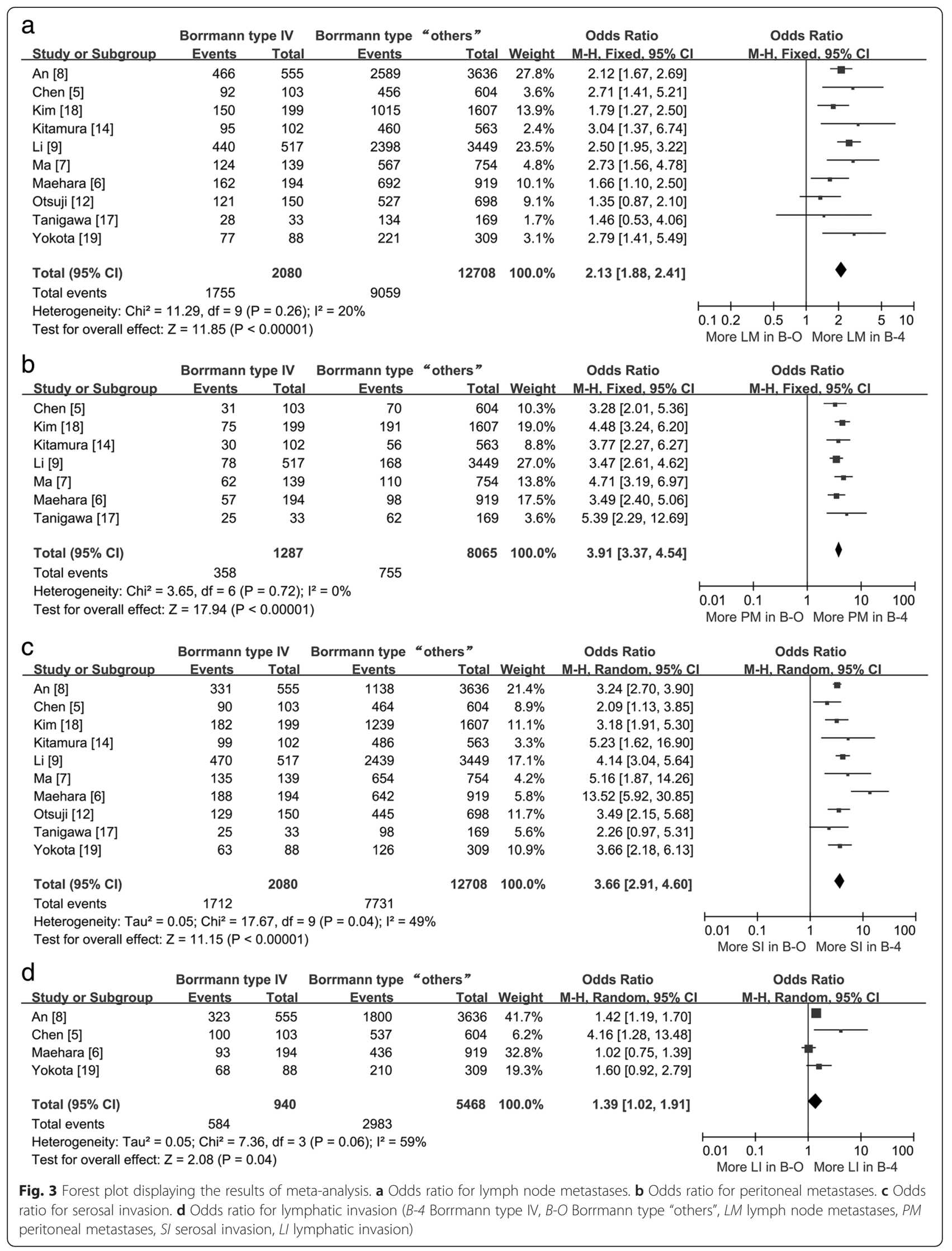




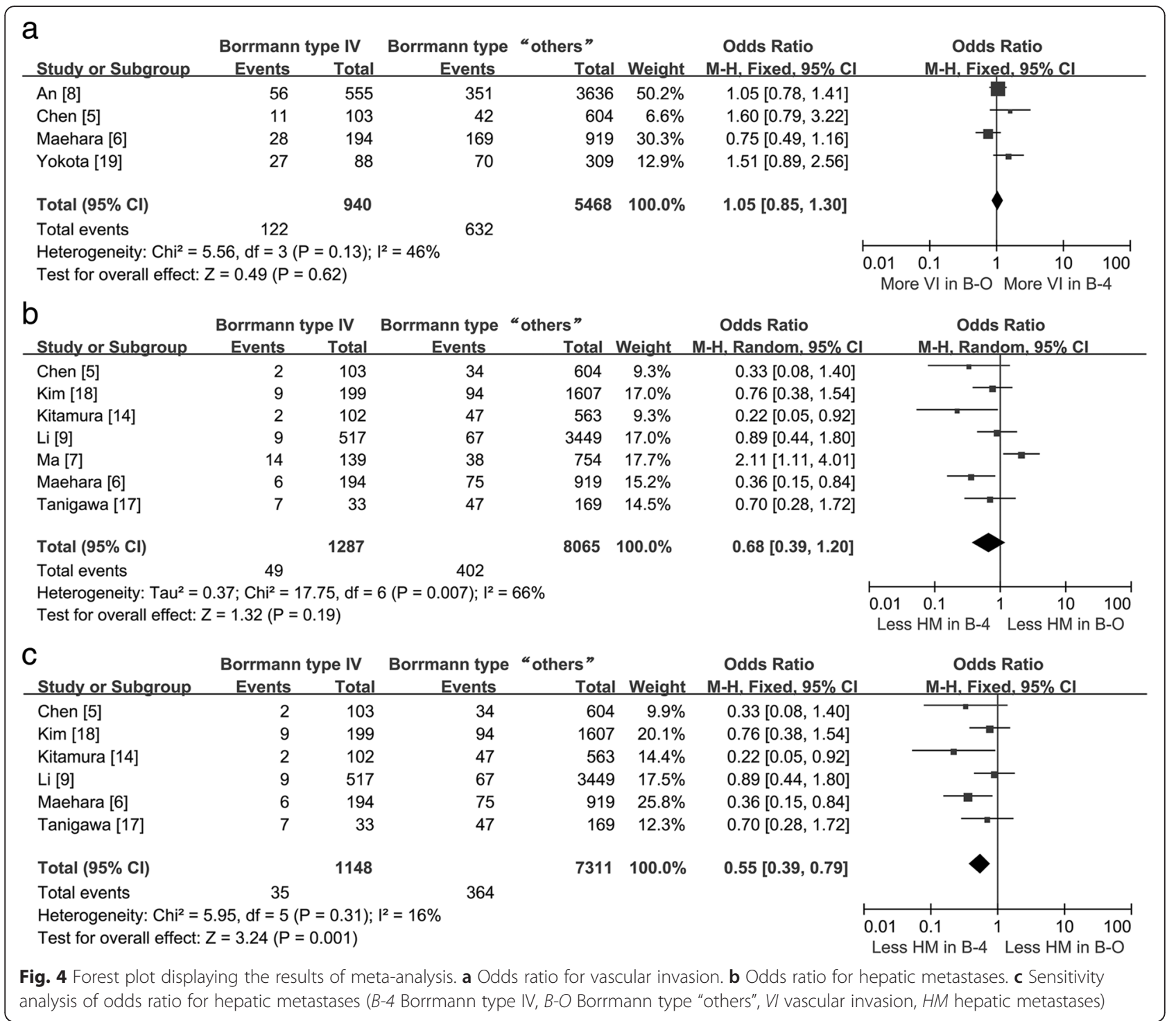

(5.2 months). This result showed that patients with noncurative resection might have a beneficial survival compared to patients with non-resection, and non-curative resection may improve the quality of life of the patients through relief of symptoms, such as bleeding, strictures, pain, or malnutrition [23]. It has also been suggested that it is not necessary to obtain a negative surgical margin at the time of a non-curative resection because patients with negative and positive resection margins of the gastrectomy with peritoneal disseminations had similar survival rates [13]; some researchers believe that for B-4 patients with peritoneal disseminations but without passage disturbance, non-curative resection should be replaced by chemotherapy [23]. However, more research into this issue is warranted before a final conclusion can be drawn. A randomized controlled trial (RCT) is designed to evaluate the superiority of non-curative resection followed by chemotherapy to chemotherapy alone in terms of overall survival [29]. We look forward to the results of this clinical trial.

Certainly, there were several limitations in our study. First, none of the studies we used in this meta-analysis were RCT studies. Patients were not randomized to noncurative resection or non-resection groups. As a result, we could not ignore the possibility that the non-curative resection group had a better prognosis than the nonresection group due to the difference in patient status; however, in the absence of RCT studies, performing a meta-analysis of retrospective studies, which represents the best evidence available, is necessary and helpful. Second, the sample sizes of some included studies were relatively small and may have weakened the statistical 


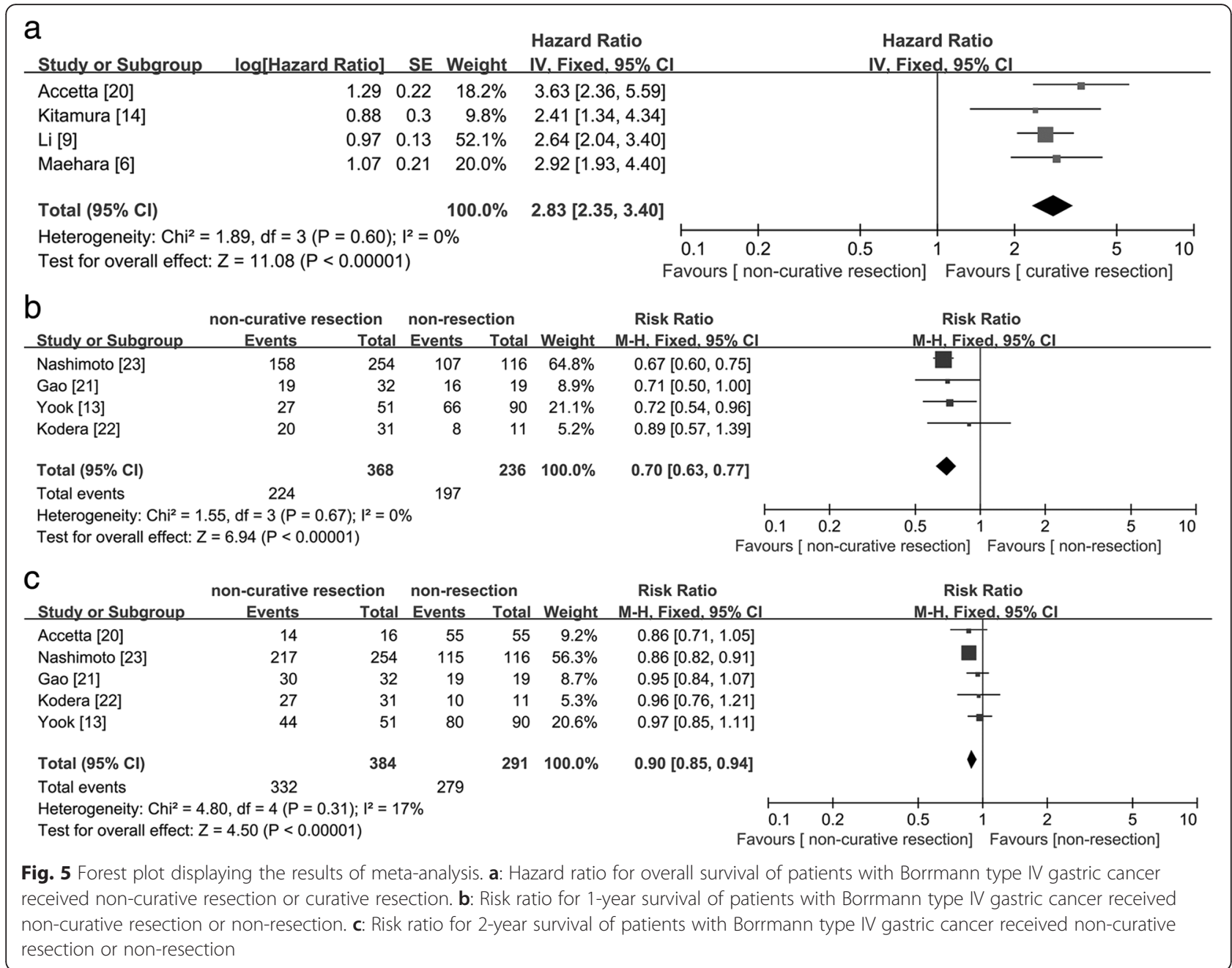

power. Third, with the exception of one study from Brazil, most of our included studies were from Asian countries; thus, the conclusions might not apply to cases outside of Asia, and the results should be further confirmed by studies involving more countries.

\section{Conclusions}

In conclusion, our meta-analysis demonstrated that B-4 gastric cancer patients had a higher female-to-male ratio, more poorly differentiated carcinomas, more lymph node metastases, more peritoneal metastases, more serosal invasion, more lymphatic invasion, and a poorer prognosis. Curative resection of B-4 gastric cancer may increase the survival rate if detected at an early stage. Even if it is not possible to perform curative resection, the effort required to perform non-curative resection may improve the prognosis of patients with B-4 gastric cancer. In the future, all of our results need further confirmation based on well-designed multi-center RCTs from more countries.

\section{Abbreviations}

B-4: Borrmann type IV; B-O: Borrmann type "others"; Cl: confidence interval; HR: hazard ratio; LUAE + Apl: left upper abdominal exenteration plus Appleby's method; OR: odds ratio; RCT: randomized controlled trial; RR: risk ratio.

Competing interests

The authors declare that they have no competing interests.

\section{Authors' contributions}

WZN and LYF participated in the design of the study. LYF, GP, LY, and MB performed the research and extracted the data. LYF, GP, SJX, SYX, HXZ, and ZJH were involved in drafting the manuscript. LYF and GP contributed equally to this work. All authors read and approved the final manuscript.

\section{Acknowledgements}

We thank the department of Surgical Oncology of First Hospital of China Medical University and the College of China Medical University for their technical assistance in this analysis.

\section{Funding}

This work was supported by Natural Science Foundation of Liaoning Province (No. 2014029201), Program of Education Department of Liaoning Province (L2014307), and Clinical Capability Construction Project for Liaoning Provincial Hospitals (LNCCC-A01-2014). The funders had no role in the study design, data collection and analysis, decision to publish, or preparation of the manuscript. 
Received: 21 September 2015 Accepted: 17 February 2016 Published online: 24 February 2016

\section{References}

1. Torre LA, Bray F, Siegel RL, Ferlay J, Lortet-Tieulent J, Jemal A. Global cancer statistics, 2012. CA Cancer J Clin. 2015;65:87-108. doi:10.3322/caac.21262.

2. Bertuccio P, Chatenoud L, Levi F, Praud D, Ferlay J, Neqri E, et al. Recent patterns in gastric cancer: a global overview. Int J Cancer. 2009;125:666-73. doi:10.1002/ijc.24290.

3. Borrmann R. Geschwulste des Magens und des Duodenums. In: Henke F, Lubarsch O, editors. Handbuch Spez Pathol Anat und Histo. Berlin: Springer Verlag; 1926. p. 812-1054. doi:10.1007/978-3-7091-5436-6_7.

4. Bollschweiler E, Boettcher K, Hoelscher AH, Sasako M, Kinoshita T, Maruyama $K$, et al. Is the prognosis for Japanese and German patients with gastric cancer really different? Cancer. 1993;71:2918-25. doi:10.1002/10970142(19930515)71. 10 < 2918:.AID-CNCR2820711006 >3.0.CO;2-V.

5. Chen CY, Wu CW, Lo SS, Hsieh MC, Lui WY, Shen KH. Peritoneal carcinomatosis and lymph node metastasis are prognostic indicators in patients with Borrmann type IV gastric carcinoma. Hepatogastroenterology. 2002:49:874-7.

6. Maehara Y, Moriguchi S, Orita H, Kakeji Y, Haraguchi M, Korenaga D, et al. Lower survival rate for patients with carcinoma of the stomach of Borrmann type IV after gastric resection. Surg Gynecol Obstet. 1992;175:13-6.

7. Ma JP, Chen JH, Cai SR, Chen CQ, Yang DJ, Wu H, et al. Clinicopathologic features and prognostic analyses of Borrmann type IV gastric cancer [In Chinese]. Zhonghua Yi Xue Za Zhi. 2012:92:2534-7. doi:10.3760/cma.j.issn. 0376-2491.2012.36.005

8. An JY, Kang TH, Choi MG, Noh JH, Sohn TS, Kim S. Borrmann type IV: an independent prognostic factor for survival in gastric cancer. J Gastrointest Surg. 2008;12:1364-9. doi:10.1007/s11605-008-0516-9.

9. Li C, Oh SJ, Kim S, Hyung WJ, Yan M, Zhu ZG, et al. Macroscopic Borrmann type as a simple prognostic indicator in patients with advanced gastric cancer. Oncology. 2009;77:197-204. doi:10.1159/000236018.

10. Okines A, Verheij M, Allum W, Cunningham D, Cervantes A. Gastric cancer: ESMO clinical practice guidelines for diagnosis, treatment and follow-up. Ann Oncol. 2010;21:50-4. doi:10.1093/annonc/mdq164.

11. Aranha G, Georgen R. Gastric linitis plastica is not a surgical disease. Surgery. 1989;106:758-62.

12. Otsuji E, Yamaguchi T, Sawai K, Sakakura C, Okamoto K, Takahashi T. Regional lymph node metastasis as a predictor of peritoneal carcinomatosis in patients with Borrmann type IV gastric carcinoma. Am J Gastroenterol. 1999;94:434-7. doi:10.1111/j.1572-0241.1999.873_b.x.

13. Yook JH, Oh ST, Kim BS. Clinicopathological analysis of Borrmann type IV gastric cancer. Cancer Res Treat. 2005;37:87-91. doi:10.4143/crt.2005.37.2.87.

14. Kitamura K, Beppu R, Anai H, Ikejiri K, Yakabe S, Sugimachi K, et al. Clinicopathologic study of patients with Borrmann type IV gastric carcinoma. J Surg Oncol. 1995;58:112-7. doi:10.1002/jso.2930580208.

15. Stang A. Critical evaluation of the Newcastle-Ottawa scale for the assessment of the quality of nonrandomized studies in meta-analyses. Eur J Epidemiol. 2010;25:603-5. doi:10.1007/s10654-010-9491-z.

16. Tierney JF, Stewart LA, Ghersi D, Burdett S, Sydes MR. Practical methods for incorporating summary time-to-event data into meta-analysis. Trials. 2007;8: 16. doi:10.1186/1745-6215-8-16.

17. Tanigawa N, Amaya H, Matsumura M, Lu C, Iki M. Association between tumor angiogenesis and Borrmann type 4 carcinomas of the stomach. Oncology. 1998;55:461-7. doi:10.1159/000011896.

18. Kim DY, Kim HR, Kim YJ, Kim SK. Clinicopathological features of patients with Borrmann type IV gastric carcinoma. ANZ J Surg. 2002;72:739-42. doi: 10.1046/j.1445-2197.2002.02523.x.

19. Yokota T, Teshima S, Saito T, Kikuchi S, Kunii Y, Yamauchi H. Borrmann's type IV gastric cancer: clinicopathologic analysis. Can J Surg. 1999;42:371-6.

20. Accetta AC, Manso JE, Mello EL, Paiva RK, Castro Ldos S, Accetta P. Type IV Borrmann gastric adenocarcinoma: analysis of curative resection results. Rev Col Bras Cir. 2011;38:237-44.

21. Gao HY, Zhang M, Wei YZ, Xue YW. The biological behavior characteristics and prognosis of Borrmann type IV gastric cancer [in Chinese]. Chinese Journal of General Surgery. 2011;26:65-6. doi:10.3760/cma.j.issn.1007-631X. 2011.01.022

22. Kodera $Y$, Yamamura $Y$, Ito $S$, Kanemitsu $Y$, Shimizu $Y$, Hirai T, et al. Is Borrmann type IV gastric carcinoma a surgical disease? An old problem revisited with reference to the result of peritoneal washing cytology. J Surg Oncol. 2001:78:175-81. doi:10.1002/jso.1144.

23. Nashimoto A, Yabusaki H, Nakagawa S. Treatment strategy for the type IV gastric cancer-from the standpoint of the surgery [in Japanese]. Jpn J Cancer Chemother. 2007;34:983-7.

24. Adachi Y, Yasuda K, Inomata M, Sato K, Shiraishi N, Kitano S. Pathology and prognosis of gastric carcinoma: well versus poorly differentiated type. Cancer. 2000;89:1418-24. doi:10.1002/1097-0142(20001001)89. 7<1418:.AIDCNCR2>3.0.CO; 2-A.

25. Maehara Y, Moriguchi S, Kakeji Y, Kohnoe S, Korenaga D, Haraguchi M, et al. Pertinent risk factors and gastric carcinoma with synchronous peritoneal dissemination or liver metastasis. Surgery. 1991;110:820-3.

26. Adachi Y, Mori M, Enjoji M, Sugimachi K. Microvascular architecture of early gastric carcinoma: microvascular-histopathologic correlates. Cancer. 1993;72: 32-6. doi:10.1002/1097-0142(19930701)72:1<32::AID-CNCR2820720108>3.0. $\mathrm{CO} ; 2-6$.

27. Furukawa $\mathrm{H}$, Hiratsuka M, Iwanaga T. A rational technique for surgical operation on Borrmann type 4 gastric carcinoma: left upper abdominal evisceration plus Appleby's method. Br J Surg. 1988;75:116-9. doi:10.1002/ bjs.1800750209.

28. Furukawa H, Hiratsuka M, Iwanaga T, Imaoka S, Ishikawa O, Kabuto T, et al. Extended surgery - left upper abdominal exenteration plus Appleby's method-for type 4 gastric carcinoma. Ann Surg Oncol. 1997:4:209-14. doi: 10.1007/BF02306612

29. Fujitani K, Yang HK, Kurokawa Y, Park Do J, Tsujinaka T, Park BJ, et al. Randomized controlled trial comparing gastrectomy plus chemotherapy with chemotherapy alone in advanced gastric cancer with a single noncurable factor: Japan Clinical Oncology Group Study JCOG 0705 and Korea Gastric Cancer Association Study KGCA01. Jpn J Clin Oncol. 2008;38:504-6. doi:10.1093/jjco/hyn058

\section{Submit your next manuscript to BioMed Central and we will help you at every step:}

- We accept pre-submission inquiries

- Our selector tool helps you to find the most relevant journal

- We provide round the clock customer support

- Convenient online submission

- Thorough peer review

- Inclusion in PubMed and all major indexing services

- Maximum visibility for your research

Submit your manuscript at www.biomedcentral.com/submit
) Biomed Central 